\title{
DE CASAS PRINCIPALES A PALACIO. LA ADAPTACIÓN DE LA RESIDENCIA NOBILIARIA MADRILEÑA A UNA NUEVA COTIDIANEIDAD*
}

\author{
NATAlia GONZÁlEZ Heras \\ Universidad Complutense de Madrid
}

Fecha de recepción: enero 2012

Fecha de aceptación: febrero 2012

\section{INTRODUCCIÓN}

Desde el presente artículo nos planteamos como objetivo principal observar la evolución que tuvo lugar a lo largo del Setecientos en las residencias habitadas por la nobleza en Madrid. Intentaremos desentrañar cuáles fueron los motivos y procesos que dieron lugar a la sustitución de las tradicionales casas principales por palacios de nueva construcción, adaptados a los nuevos usos y gustos en boga.

La intencionalidad de este estudio se aleja de los planteamientos desarrollados desde la disciplina artística, centrada fundamentalmente en el análisis de los aspectos formales y estéticos, relativos a las estructuras arquitectónicas. Por el contrario, se pretende una aproximación a las transformaciones que sufrieron las prácticas de vida cotidiana de quienes habitaban dichas residencias, a través del estudio de la evolución material de sus viviendas. Un ámbito doméstico que se encontraba inmerso en un profundo proceso de cambio, condicionado a atender las nuevas necesidades, así personales como sociales, de un grupo nobiliario, que asimismo, estaba cambiando.

Para ello analizaremos un conjunto de viviendas nobiliarias de cuyas características se ha conservado testigo en diferentes tipos de fuentes -notariales, fiscales, iconográficas-.

\footnotetext{
* Este trabajo se realiza en el marco de una Beca Predoctoral de Formación de Personal Investigador (FPI), vinculada al Proyecto de Investigación FFI2008-02276/FISO El nacimiento de la esfera pública (1680-1833): Bases socio-profesionales y pautas culturales en la Monarquía española, financiado por el Ministerio de Ciencia e Innovación.
} 
La finalidad de elegir el siglo XVIII, en toda su amplitud, como marco cronológico, radica en la necesidad de observar dentro de un período lo suficientemente extenso, la evolución de nuestro objeto de estudio y poder comparar los modelos existentes en los diversos momentos.

\section{APUNTES GENERALES SOBRE LA NOBLEZA MADRILEÑA Y SUS VIVIENDAS}

La nobleza representaba un grupo significativo, tanto en términos cualitativos como cuantitativos, dentro de la sociedad madrileña del siglo XVIII. La Corte constituía un núcleo urbano receptor y de residencia habitual de este estamento que, tradicionalmente, desarrollaba su actividad en torno al monarca.

En el presente estudio hemos decidido integrar en el grupo social nobiliario a un conjunto de individuos que disfrutaban de título; sin entrar a realizar distinciones entre aquellos que formaban parte de la aristocracia tradicional y los recién incorporados al estamento, mediante la concesión de títulos llevada a cabo por la Monarquía en compensación a sus oficios y servicios desempeñados en la administración del Estado o el Ejército. El análisis de las viviendas de unos y otros nos ha de permitir conocer y calibrar la incidencia del cambio de modelo doméstico que planteamos como hipótesis de partida, dentro de la jerarquía del grupo aristocrático; así como observar si los niveles alcanzados dentro del terreno de lo doméstico por aquellos individuos en ascenso, se adaptaban a la consolidada idea de «levantan soberbios edificios los que no tienen solar conocido y se están cayendo las casas de los que mil años ha, comen en plata los que ayer no tenían más hacienda ni de dónde viniese que un cajón de secretaría con quince o veinte escudos de sueldo» ${ }^{1}$.

\subsection{Una nobleza de corte}

En contraposición a la dinámica seguida por las aristocracias de otros territorios europeos, que mantenían un estrecho vínculo con sus propiedades solariegas, donde pasaban aún largas temporadas y en las que invertían importantes cantidades económicas en la construcción y mantenimiento de magníficas casas de campo ${ }^{2}$, la nobleza española había hecho de la capital madrileña su lugar permanente de residencia. En palabras de Pedro Navascués: «ni la nobleza ni la alta burguesía habían sentido - yo creo que desde nunca- interés por la vida y el contacto con la naturaleza y el campo del que ellos mismos eran sus propietarios» ${ }^{3}$.

Asimismo, los testimonios de algunos viajeros extranjeros son muy ilustrativos al respecto:

1. Biblioteca Nacional (BN), Manuscrito (Mss) 8160, fol. 66.

2. Sobre este fenómeno GIROUARD, Mark: Life in the English Country House. A social and architectural History. Yale University Press, 1978.

3. NAVASCUÉS PALACIO, Pedro: «La Alameda de Osuna: una villa suburbana». Estudios Pro-Arte, núm. 2, Barcelona, 1975, p. 7. 
«Todos esos hermosos castillos de la nobleza se caen en ruinas en todas las provincias de España, mientras sus propietarios van a llevar las cadenas en la capital y a aumentar el fasto de la corte y la autoridad del príncipe» ${ }^{4}$.

Tomando estas afirmaciones como punto de partida, pasamos a considerar fundamental el análisis de sus viviendas en Madrid como fiel reflejo de las formas relativas a su existencia doméstica cotidiana.

\subsection{El cambio de modelo}

El siglo XVIII fue testigo de una dicotomía en lo que a la morfología de la vivienda nobiliaria se refiere. A partir de la segunda mitad de la centuria, en la capital madrileña empezaron a coexistir las tradicionales casas principales, en las que venían habitando las familias nobles desde hacía siglos, y los palacios de nueva construcción.

El concepto de casas principales es aquél con el que encontramos registradas en la mayor parte de la documentación, hasta aproximadamente mediados de siglo, las viviendas de los nobles. El término suele aparecer en plural, puesto que hace mención a su composición por varios edificios: la casa principal, donde habitaban los señores, y las accesorias, que servían de residencia a los miembros del servicio, de caballerizas, cocheras, almacenes... Muchas de estas casas sufrieron reformas estructurales y obras de remodelación durante el siglo XVIII. La finalidad era adaptarlas a los nuevos modelos y usos del período. No obstante, su ubicación dentro de la retícula urbana de la capital y la falta de terreno, dificultaron las readaptaciones de las mismas a los patrones arquitectónicos ilustrados y a las necesidades de uso emergentes.

Por su parte, un nuevo tipo de construcción comenzó a surgir a partir de la década de los 60 -con el inicio del reinado de Carlos III-, la casa-palacio. María Victoria López-Cordón, en su trabajo «Casas para administrar, casas para deslumbrar», desarrolló un análisis magistral de la evolución del concepto palacio y cómo éste adquirió una serie de nuevas connotaciones durante aquel período ${ }^{5}$. Las nuevas casas-palacio se proyectaron, bien, en los límites suburbanos de la ciudad, bien, en solares intramuros resultantes de los derrumbes de construcciones anteriores. La intencionalidad era contar con zonas espaciosas, en las que construir viviendas exentas y de grandes dimensiones, rodeadas de un espacio natural al que cada vez se le concedía mayor valor, el jardín.

La nobleza, en muchos casos, pretendió imitar con sus nuevas viviendas los palacios de la Monarquía, llegando a temer esta última que tal emulación pudiera llegar a hacerla sombra. Este hecho se ejemplifica, entre otros, a través del caso del palacio de la Marquesa de Astorga, cuya finalización nunca tuvo lugar, y que se atribuyó por unos a la falta de medios económicos en que cayó la familia, mientras, otros lo percibieron

4. DALRYMPLE, William: «Viaje a España y Portugal» en GARCíA MERCADAL, José, Viajes de extranjeros por España y Portugal. III. Siglo XVIII. Madrid, 1962, p. 680.

5. LÓPEZ-CORDÓN CORTEZO, María Victoria: «Casas para administrar, casas para deslumbrar: la pedagogía del palacio en la España del siglo XVIII» en REY CASTELAO, Ofelia y LÓPEZ, Roberto J., El mundo urbano en el siglo de la Ilustración, vol. II, Santiago de Compostela, 2009, p. 23 y ss. 
como resultado de los frenos interpuestos por parte del Monarca, temeroso de que un palacio nobiliario pudiera ensombrecer su Palacio Real ${ }^{6}$.

\section{LAS CASAS PRINCIPALES}

Para comprender las características propias de las casas principales madrileñas, se ha seleccionado un conjunto de casos que nos aportan datos sobre sus rasgos fundamentales.

Antes de introducirnos en las particularidades de la casuística, es importante apuntar que los casos que se han tomado y en los que las residencias aparecen denominadas como casas principales, se circunscriben cronológicamente - de forma aproximada- a la primera mitad del siglo XVIII. De forma que, entendemos que las casas principales constituían una realidad continuista con los modelos barrocos del siglo precedente, que se extendieron hasta bien avanzado el Setecientos ${ }^{7}$.

\subsection{Las «casas principales» del Príncipe Pío de Saboya ${ }^{8}$}

Don Francisco Pío de Saboya Moura y Corte Real, tradicionalmente conocido como el Príncipe Pío, murió el 15 de septiembre del año 1723, como víctima de una riada en la capital madrileña. En aquel momento ocupaba el cargo de Gobernador y Capitán General de Cataluña, al cual había accedido tras una larga trayectoria castrense y administrativa 9 .

La residencia que habitaba junto a su esposa, doña Juana Spínola y la Cerda, y los cuatro hijos del matrimonio -Gisberto, Leonor, Isabel y Lucrecia-, todos menores de edad, se encontraba situada en la calle de Hortaleza, correspondiente a la circunscripción parroquial de la iglesia de San Luis, anejo de la parroquia de San Ginés.

Se trataba de una casa alquilada, por la que pagaba 300 doblones anuales, de cuya distribución espacial interior conocemos muy poco. Sin embargo, mediante el análisis de los objetos que la componían, que aparecen en el inventario de bienes postmortem del Príncipe Pío ${ }^{10}$ agrupados por categorías -fundamentalmente, relativas a los materiales de que estaban hechos, aunque también atienden en algún caso a su función

6. Martínez MedinA, África.: «La casa palacio del Marqués de Astorga» en Anales del Instituto de Estudios Madrileños. XXVII (1989), pp. 121-133 y Palacios madrileños del siglo XVIII. Madrid, 1997, pp. 61-72.

7. GONZÁLEZ HERAS, Natalia: «La permanencia barroca. Apariencia, escenografía y teatralidad en la vivienda aristocrática madrileña de comienzos del siglo XVIII». Comunicación presentada en las V Jornadas de Historia Cardenal Portocarrero: Permanenecias y cambios en la Historia, Palma del Río (Córdoba), octubre de 2009.

8. Sobre la influencia de los modelos italianos en la vivienda de Príncipe Pío, GonZÁlez Heras, Natalia «La influencia de los modelos culturales italianos en el ámbito doméstico: las casas principales del Príncipe Pío de Saboya en el Madrid del siglo XVIII» en MARTínEZ Millán, José y Rivero RodríGUEZ, Manuel. (coords.) Centros de poder italianos en la Monarquía Hispánica (siglos XV-XVIII). Vol. III. Madrid, 2010. pp. 2005-2024.

9. Ibídem, pp. 2012-2013.

10. Archivo Histórico de Protocolos de Madrid (AHPM). Protocolo ( $\mathrm{P}^{\circ}$ ). 14938. Folio (f.) 330 y ss. 
específica -cortinaje, camas, alfombras-, interpretamos que nos encontramos ante una vivienda que habría de cumplir una importante función pública y de representación. La zona de respeto, aquélla en la que la familia recibía, se compondría, entre otras estancias, por un salón en el que dar cabida a un nutrido grupo de invitados. Estos tomarían asiento en las sillas, taburetes y canapés de madera, policromados en blanco y con filetes dorados, cuyas cubiertas iban a variar según la estación del año o el evento que se celebrara -sustituyéndose los damascos de diferentes colores, por tafetanes, rasos, todos ricamente adornados con hilos de oro-.

Aquellos invitados serían agasajados, a su vez, con un banquete, al que nos acerca el elevado número de servicios de plata y porcelana que se inventariaron, o con un té, café o chocolate, servido en jícaras de porcelana siempre acompañadas por un platillo en el que sostenerse, aunque todavía no aparezca su denominación específica como mancerinas. En estas ocasiones el centro de la sala se habilitaría con distintos tipos de mesas, de cuidadas y sofisticadas tallas, en maderas nobles como el nogal o la caoba, cuya posibilidad de ser plegadas y desplegadas - por tener la característica de doblarse- permitiría que cuando su función terminara pudieran ser retiradas, dejando libre el centro de la estancia; dando lugar a espacios de gran amplitud en los que la escasez de mobiliario era la tónica general, apareciendo los muebles colocados junto a las paredes. Probablemente, las paredes de aquella sala se encontrarían cubiertas por alguno de los tapices que componían la colección del señor de la casa o por alguna de las pinturas en las que el tema religioso, con frecuencia uno de los más representados, se veía, en cierto modo, relegado por diferentes países. Ventanas y puertas de balcones iban a aparecer cubiertas por cortinas, colgaduras y sobrepuertas, elaboradas en damascos y tafetanes, similares a los de las cubiertas de los asientos de la sala.

La temperatura de la estancia se acondicionaría mediante una chimenea de estilo francés, cuyos adornos también se registraron en el inventario:

«Adornos de talla para chimeneas:

La madera de una chimenea a la francesa blanca con molduras doradas y el fondo labrado de quadrado con unas florecillas de talle y obradas con su christal pero quebrado

El armazón de otra chimenea a la francesa maior que la antecedente de blanco con sus molduras y otros adornos de talla sobredorados con una pintura en el medio de unos muchachos y esta no tiene christal» ${ }^{11}$.

Otra de las estancias comprendidas dentro de la zona de respeto a la que nos introduce el inventario de bienes, es una cámara o alcoba de aparato o representación. En ella se ubicaría una de las camas imperiales que se anotaban entre los bienes inventariados. Vestida en damasco con remates en oro, se compondría de cielo, cortinas, rodapiés y cavezera con las armas de Pío y Castel Rodrigo ${ }^{12}$. La riqueza de este tipo de de mueble y sus vestiduras - donde se recreaba el escudo de armas de la familia- muestran

11. AHPM. $\mathrm{P}^{\circ} 14938$, f. 337.

12. AHPM. $\mathrm{P}^{\circ} 14938$, f. 334. 
estar hechos para ser vistos por quienes visitaban la vivienda, erigiéndose en reflejo del distinguido nivel de los moradores de la casa.

\subsection{Las «casas principales» del Infantado en la costanilla de San Andrés}

Localizadas en el perímetro que la Planimetría General de Madrid establece como la manzana número $130^{13}$, ocupándola en su totalidad, con fachadas a la costanilla de San Andrés, la calle de los Dos Mancebos y la calle de la Redondilla, la casa principal que el X Duque del Infantado ocupara en la capital madrileña, venía cumpliendo con esta función dentro de su familia desde que la VI duquesa del Infantado decidiera establecer su residencia en la Corte más de un siglo antes ${ }^{14}$.

Los datos que procederemos a analizar en este apartado proceden del inventario de bienes realizado con motivo de la muerte en 1737 de doña María Teresa de los Ríos Zapata y Córdoba ${ }^{15}$, esposa del referido X duque del Infantado, don Juan de Dios Silva de Mendoza. Este inventario de bienes post-mortem muestra la ventaja de que, además de ofrecernos una detallada relación de los bienes contenidos en la vivienda, el escribano fue agrupándolos por estancias. Nos acerca, por lo tanto, hasta cada uno de los aposentos de la vivienda y anota, a continuación, los objetos contenidos en ellos; permitiéndonos así, una reconstrucción bastante fiel del interior de la casa.

Comenzaremos apuntando que dichos interiores mostraban en algunas de sus estancias una diferenciación individual o personal, es el caso de cuando en la escritura se distingue entre el cuarto del Duque y el de la señora Duquesa, hallando en cada uno de ellos mobiliario y objetos propios de las actividades que se asociaban a sus titulares. En el del Duque, así como en la pieza que le precedía, una antecámara, predominaban los diferentes tipos de mesas -de armar, papelera, bufete- que se completaban con su correspondiente escribanía, signo indicativo de la dedicación de su propietario al trabajo con documentos -lectura, escritura-. A la vez, aparecían vinculados a este cuarto diversos objetos preciosos, consistentes en dos juegos de mesa labrados en plata y un conjunto de relojes de sobremesa, dos de ellos de Inglaterra.

Mientras, al cuarto de la Duquesa aparecían ya ligados aquellos pequeños espacios que constituían los gabinetes, guardarropas... y que estaban avanzando el nuevo concepto de vivienda nobiliaria compuesta por apartamentos. Unos apartamentos que se caracterizaron por la diferenciación sexual y que dieron lugar a la aparición de dos zonas diferenciadas dentro del palacio, la masculina, formada por la cámara del señor y un conjunto de pequeños compartimentos anejos a aquélla, y la femenina, de similar estructura, pero para la señora de la casa. El modelo del apartamento, con claros precedentes franceses, se iba a proyectar sobre todo en las nuevas construcciones palaciales sobre las que trataremos más adelante. No obstante, hemos de mencionar que la

13. BN, Mss 1672, Planimetría General de Madrid. Libro segundo de los asientos de las casa de Madrid, p. 119.

14. Martínez Medina, África: Palacios madrileños... op. cit. p. 141.

15. AHPM. Po 14916 f. 1. 
casa del Infantado dejó constancia de dicha estructura en sus casas principales de las Vistillas, las cuales, tras dos siglos de remodelaciones, acabaron constituyéndose en la última década del siglo como modelo palacial con las reformas que la princesa de Salm Salm, viuda del XII duque del Infantado, desarrollara en ellas ${ }^{16}$. A continuación, se presenta el plano de este palacio en una etapa previa a su última remodelación y en la que todavía mantenía el carácter de casa principal; asemejándose su planta a la que podría tener la vivienda del mismo título junto a San Andrés, que analizamos en este apartado (Figura 1).

Pese a los signos que acabamos de mencionar y que pueden entenderse como un avance de lo que se va a consolidar algunas décadas más tarde, los espacios de carácter público que formaban parte de estas casas principales se mantenían fieles a la tradición a través del estrado. Estos lugares, concebidos como espacios para la reunión de mujeres y que bien podían entenderse como reductos de segregación femenina, se mantenían en las casas principales del duque del Infantado en San Andrés en 1737 y aparecían amueblados con sitiales, almohadas y alfombras -calificadas con el adjetivo viejas, lo que nos remite a su permanencia durante años-.

Por otra parte, la piedad de la familia aristocrática también encontraba espacio en la vivienda, más allá de la pintura de carácter religioso, predominante dentro de las colecciones pictóricas que albergaban dichas residencias, algunas casas nobiliarias se dotaban de un oratorio para su uso privado y en el que celebrar ceremonias de carácter íntimo. Para el caso de los Infantado, debido a la ubicación de su casa principal junto a la iglesia de San Andrés, además del referido oratorio privado, del que queda reflejo en la escritura notarial, está documentada la construcción de un pasadizo que les permitiera tener acceso directo desde su vivienda a dicha iglesia. Era éste un modo de demostrar su preeminencia social e incluso equipararse a la realeza, que acometió obras de este tipo para tener acceso desde algunas de sus residencias a ciertas iglesias y conventos. El inventario de bienes deja constancia de ello cuando hace referencia a una cortina de paño entrapado encarnado con galón de seda al canto... que sirve en la tribuna ${ }^{17}$, si como afirma Martínez Medina ésta era la tribuna que comunicaba la iglesia con la vivienda ${ }^{18}$.

\subsection{La casa del Marqués del Rafal}

El Marqués del Rafal, don Antonio de Heredia Bazán, representa uno de esos casos de funcionario de la alta administración central del Estado que disfrutaba de un título nobiliario.

\footnotetext{
16. Martínez MedinA, África: «El palacio del Duque del Infantado en las Vistillas. Su definitiva configuración en el siglo XVIII» en Anales del Instituto de Estudios Madrileños. XXVIII, (1990), pp. 85-101 y Palacios madrileños... op. cit., pp. 164-188.
}

17. AHPM. Po 14916, f. 15.

18. MartíneZ Medina, África: Palacios madrileños... op. cit., p. 142. 


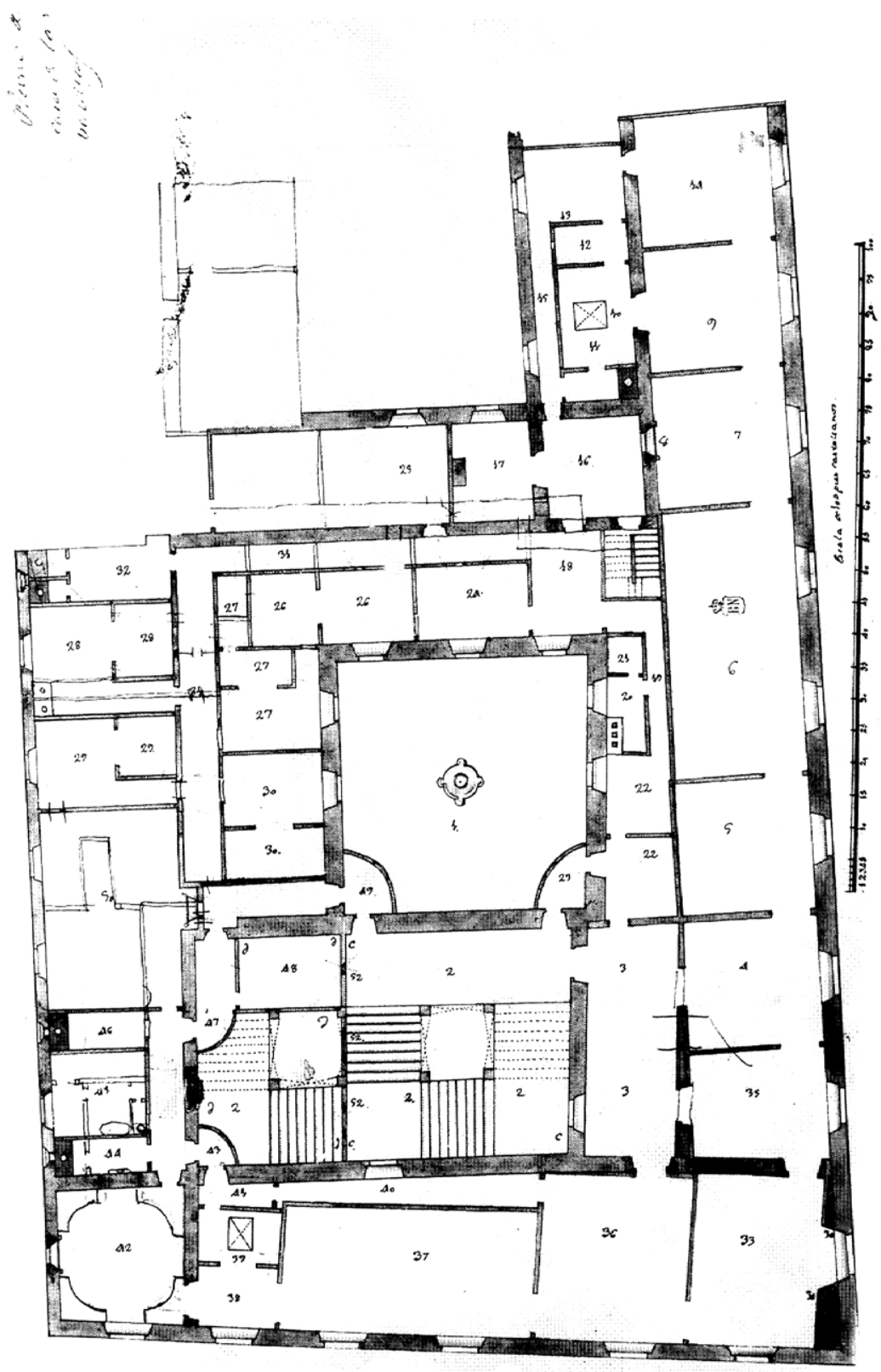

Figura 1. Plano de la casa de las Vistillas ${ }^{19}$

19. BN. DIB 14/45/60. A. Martínez Medina describe el dibujo como: «una gran planta central con dos alas que sobresalen. La programación del espacio se hizo alrededor del gran patio central conformándose el 
Se accede al conocimiento de la vivienda que este miembro del Consejo Real de Hacienda, además de Corregidor de la villa de Madrid, disfrutaba en la capital, a través de la escritura de inventario y tasación de bienes realizada en 1753 con motivo de su muerte $^{20}$. En ella había habitado junto a su esposa, doña Antonia María Rocamora y Heredia-fallecida en 1751-y los dos hijos del matrimonio, don Antonio, heredero del título nobiliario, y doña Antonia.

Dicha escritura no nos ofrece datos específicos acerca de la distribución de los espacios interiores domésticos, sin embargo, a través de los muebles y objetos que aparecen anotados, percibimos, una vez más, la existencia de unos espacios destinados a la representación: salas de recibir iluminadas mediante arañas y cornucopias de cristal, en las que dar cabida a los conjuntos de asientos que formaban canapés, sillas de brazos y taburetes, tallados en nogal y cubiertos de damasco; así como a las mesas, muestra del grado de complejidad alcanzado por el arte de la ebanistería. El uso de este mobiliario no quedaba limitado a la sala de recibir, sino que su presencia se repetía en otras estancias como el gabinete o alguna antecámara. Se trataba, por tanto, de muebles polivalentes, de posible uso en diferentes piezas, lo cual no significa que no se caracterizaran por la especialización en la función que debían cumplir, sino que dentro de la vivienda nobiliaria la función de recibimiento quedaba extendida por la mayor parte de sus estancias, aunque no a todas ellas tuvieran acceso las mismas personas. Algunas, como los gabinetes o las antecámaras previas a las alcobas, poseían un carácter más «íntimo», y el paso sólo les estaba permitido a las personas más allegadas; una condición de la que carecían las antesalas y las salas, abiertas a un público mayor.

No obstante, no todo lo inventariado dentro de las casas principales denotaba lujo y ostentación, por el contrario, también se hallaban muebles realizados en maderas de calidad inferior como el pino o sillas de paja, que habrían de servir en piezas de primera necesidad como la cocina o aquéllas destinadas al personal de servicio.

La misma dicotomía que en la calidad del mobiliario, se encontraba reflejada en los tejidos de los cortinajes que cubrían ventanas y balcones en las distintas estancias de la vivienda. Los de las zonas de represtación de la vivienda se caracterizaban por el mayor valor económico de sus telas, en algunos casos incluso de importación:

«Una colgadura de seda y estambre de portanova de Italia con cinquenta y seis paños y nuebe pedazos de lo mismo para sobre puertas campo azul en dos mil y doscientos reales Otra colgadura de catre de la misma ropa en ciento y cinquenta reales

edificio como un bloque compacto en el que se había establecido un eje: «entrada, zaguán, escalera, vestíbulo y patio»... La planta se dividió en tres zonas perfectamente diferenciadas; zona noble compuesta por zaguán, escalera principal, vestíbulo o recibimiento como figura en el dibujo con los números 2 y 3 , desde él se daría paso a las antecámaras y a los grandes salones a los que les corresponderían en el plano los número 4, 5, 6, 7 y 9. La zona privada estaba situada al otro lado del patio y estaba compuesta por dormitorios dispuestos en «alcobas de nicho». Entre estas dos zonas se establecía alrededor del patio un área intermedia, configurada por pequeños salones denominados aun «salones de estrado»»), en MARTíNEZ Medina, África: Palacios madrileños... op. cit. p. 171.

20. AHPM. Po 14962, f. 951. 
Otra colgadura de lo mismo campo berde y flores doradas con veinte y tres paños en novecientos reales ${ }^{21}$.

Sin embargo, los de las zonas destinadas o frecuentadas principalmente por el servicio estaban hechos en telas de fabricación nacional, de calidades y precios inferiores.

Similar diferencia se aprecia en los juegos de cama y mesa que utilizaban los señores y los que eran para el uso de la servidumbre doméstica. Se muestra de este modo, cómo la vivienda nobiliaria daba cabida en su interior a dos realidades muy diferentes: la de la riqueza y el lujo de que disfrutaban los señores y los niveles materiales inferiores que se destinaban a los miembros del servicio.

Finalmente, incidiremos en algo que ya se ha apuntado en líneas anteriores, la presencia de elementos extranjeros dentro de esta vivienda. El gusto por lo foráneo quedaba aún más patente a través de un gran tapiz, procedente de Amberes, que, probablemente, cubriría las paredes de la sala principal de recepción, o mediante una alfombra turca. Elementos decorativos ambos, que además cumplían con la tradicional función de aislantes de paredes y suelos, protegiendo las estancias del frío del exterior y conservando mejor el calor generado por la chimenea francesa a la que solía reservársele un sitio en este tipo de salas.

\subsection{Las «casas principales» del Marqués de Portago en la calle del Príncipe}

Don José Gómez de Terán, Marqués de Portago, falleció en 1754 siendo Ministro del Tribunal de la Contaduría Mayor y Consejero del Consejo Real de Hacienda ${ }^{22}$. El testimonio acerca de su vivienda, que nos facilita su inventario de bienes postmortem $^{23}$, nos aproxima a su casa principal en la calle del Príncipe. Aquélla, que tenía también fachada a la calle del Lobo, se encontraba libre de toda carga y contribución y fue tasada en 508.104 reales. Junto a dicha casa principal, residencia de don José y su esposa - doña Juana Paula García de Lamadrid- aparecía también la tasación de unas casas accesorias, en las que estaban ubicadas las caballerizas y cocheras, cuyo valor, del que se bajaban los 4 ducados de carga de aposento real cobrados anualmente, quedaba en 146.958 reales y 16 maravedíes.

La vivienda principal contenía una importante colección pictórica muy diversificada temáticamente, añadiendo a la tradicional abundancia de pintura religiosa -imágenes de Vírgenes, la Sagrada Familia, Cristos y Santos-, naturalezas muertas -bodegones de flores, frutas-, diferentes tipos de países -marítimos, de ciudades-, batallas, retratos -de la realeza, de personajes antiguos-, pintura mitológica, faunística. La mayor parte de las obras inventariadas aparecían acompañadas del adjetivo original, apreciable también esta característica por sus elevados precios. En determinados casos se especificaba quién era su autor, señalándose obras de Morales, Murillo, hasta veintiuna batallas del Borgoñón, la brocha de uno de los Brueghel -sin especificar cuál de

21. AHPM. Po. 14962, f. 882.

22. Sobre su trayectoria político administrativa FICHOZ 011025.

23. AHPM. Po 16741, f. 349. 
ellos- Labrador, Pereda y otras atribuidas a artistas de las escuelas italiana o flamenca, sin dar detalle de su autor. Por lo tanto, podríamos considerar a este Marqués-Consejero de Hacienda como un importante coleccionista de pintura, de cuya afición se hallaba reflejo en su vivienda, en la que las paredes de las distintas estancias se vestían con los mencionados cuadros de diferentes formatos - mayor o menor tamaño, cuadrados, rectangulares u ovalados-. Pese al avance del siglo, acompañando a las pinturas como elementos decorativos, se mantenían los tradicionales tapices, que conservaban también su función de aislantes térmicos:

«Una tapicería de trece paños Historia del Triunfo de la Fe que tiene trescientas ochenta y tres anas en cuadro y además ocho sobrepuertas con cuarenta y dos annas en 25.530

Otra de quince paños Historia de Alejandro, fábrica de Amberes 16.500

Otra de doce paños Historia de David en 17.475

Otra de ocho paños fábulas de Cupido con cuarenta y cuatro annas en 10.890

Otra de seis paños Historia de David entrefina que está en Barajas en 2.000» ${ }^{24}$.

Asimismo, similares funciones -térmica y decorativa a la vez-eran atribuibles a las alfombras que vestían el suelo, procedentes de exóticos países:

«Una alfombra turca maltratada de doce baras y dos tercias de largo en 3.255

Otra también turca de segunda suerte de diez baras de largo en 1.500

Otra fina de la India de once baras en 1.759

Otra del Cairo de ocho baras en 1.925

Otra fina turca maltratada de cinco baras en 300

Otra fina del Cairo de seis baras y cuarta en $300 »^{25}$.

Los muebles de la vivienda eran acordes a la calidad que colgaba de sus paredes y cubría sus suelos. Destacaremos los conjuntos de asientos compuestos por sillas y taburetes de Inglaterra, caracterizados por la red en el asiento y el respaldo. Su existencia nos permite afirmar el gusto por el mobiliario de importación entre los miembros de los grupos preeminentes de la sociedad, aquellos que podían permitirse conocer las tendencias extranjeras y acceder a ellas, pese a sus altos costes, en comparación con las de fábrica nacional.

\section{LOS PALACIOS}

La documentación correspondiente a la segunda mitad de la centuria comienza a aportar las primeras referencias sobre las nuevas construcciones de carácter palacial.

Ya se hizo alusión anteriormente a la necesidad de contar con terrenos lo suficientemente amplios como para materializar aquellos nuevos modelos constructivos por los que se abogaba desde la teoría arquitectónica. En algunos casos se aprovecharon terrenos suburbanos para construir en las afueras de Madrid verdaderas villas de recreo como la Alameda de Osuna o el «Capricho» de los Condes-Duques de Benavente ${ }^{26}$, el

24. AHPM. $P^{\circ} 16741$, f. 372-373.

25. AHPM. Po 16741, f. 373.

26. NAVASCUÉs PALACIO, Pedro: Op. cit. 
Palacio de la Florida del Príncipe Pío o la Moncloa, que perteneció primero a la duquesa de Arcos y que después heredó su hija la duquesa de Alba.

Por el contrario, cuando este tipo de construcciones quisieron llevarse a cabo en zonas interiores de la villa, tuvo que procederse al derrumbe de edificios existentes, lo que dio lugar a importantes modificaciones de la retícula urbana.

\subsection{El palacio de Buenavista de la casa de los Alba}

Un caso que ejemplifica el procedimiento al que se acaba de hacer mención es el del palacio de Buenavista. Esta vivienda palacial tuvo su origen, como tantas otras de la época en la capital, en una casa principal previa y sus accesorias. La casa principal sobre la que después se proyectó el palacio databa del siglo $\mathrm{XVI}^{27}$ y había sido habitada en las últimas décadas por don Zenón de Somodevilla, Marqués de la Ensenada, y a continuación por la reina viuda Isabel de Farnesio. Fue a su muerte cuando el XII duque de Alba, don Fernando de Silva Álvarez de Toledo, adquirió dicho edificio y comenzó un proceso de compra de las propiedades colindantes ${ }^{28}$. La finalidad era la demolición de los inmuebles y el aprovechamiento de sus solares en la construcción del nuevo edificio palacial. Martínez Friera relacionó las diversas compras de inmuebles, que fueron realizando de forma sucesiva el duque don Fernando y su heredera, la duquesa doña María del Pilar Teresa Cayetana, en los terrenos colindantes a la vivienda principal original, cada una de ellas con una finalidad, unas para su derrumbe y otras para su aprovechamiento como accesorias, incluso, destinadas a servirles de residencia durante los años que permanecieran las obras de construcción del nuevo palacio ${ }^{29}$. Así pues, el matrimonio formado por la duquesa de Alba y su esposo, don José María Álvarez de Toledo, Marqués de Villafranca y Duque de Medina Sidonia habitó, una vez se ordenó el derrumbe de la antigua casa principal y mientras se desarrollaban las obras del nuevo palacio, la vivienda número 3 de la manzana 307, la cual había servido de morada al embajador de Portugal ${ }^{30}$.

27. Para conocer sus antecedentes vid. DADSON, Trevor: «Un palacio para un conde: la compra y rehabilitación del palacio de Buenavista por Diego de Silva y Mendoza, conde de Salinas», Cuadernos de Historia Moderna, vol. 33 (2008), pp. 61-88.

28. Se ha tenido acceso a una escritura de venta de vivienda en la que don Fernando de Silva Álvarez de Toledo, duque de Alba, compraba a finales del año 1769 una casa sita en la calle del Barquillo, esquina a la de la Emperatriz y que sube a la de Buenavista vendida por don Luis Curiel, Conde de San Rafael. AHPM. Po 18694, f. 405.

29. Siguiendo el texto de MARTínez Friera, J.: Historia del palacio de Buenavista. Hoy día Ministerio del Ejército. Madrid, 194?. Anotamos los datos correspondientes a las escrituras de compra-venta de viviendas contiguas a la principal de Buenavista: 19 de octubre de 1769 ante Diego Trigueros, 26 de octubre de 1769 ante Félix Rodríguez, 13 de noviembre de 1769 ante Manuel Gómez Guerrero, 20 de diciembre de 1769 ante Juan Francisco González, 20 de diciembre de 1769 ante Matías Culebra y Acero, 13 de enero de 1770 ante Bruno Saenz de Arellano; y ya en tiempos de su nieta y heredera 1 de enero de 1793 ante don Miguel Tomás París y 24 de octubre de 1795 ante don José Fernández de Uceda. Todas ellas en el Archivo Histórico de Protocolos de Madrid.

30. Ibídem. p. 282. 
La construcción del nuevo palacio de Buenavista se encomendó al arquitecto Pedro Arnal, estableciéndose como finalidad la realización de una obra que materializara los nuevos modelos y patrones necesarios para cubrir aquellas necesidades que se iban poco a poco estableciendo como indispensables en el vivir cotidiano doméstico de una familia de la nobleza de la de los Alba. Debía consistir en un palacio de una magnificencia tal, que reflejara la grandeza de aquel linaje. Adaptado a la función cortesana que desempeñaban sus propietarios, don José María, Gentilhombre de Cámara al servicio del Príncipe de Asturias, y doña María del Pilar, asistente a las reuniones que tenían lugar en las habitaciones del Príncipe don Carlos y su mujer la Princesa María Luisa $^{31}$. Sus salones estaban destinados a dar cabida a encuentros y fiestas a los que iban a asistir los miembros de la elite -nobiliaria, administrativa, cultural-de la capital. No obstante, a su vez, tenía que estar adaptado para cubrir la necesidad de espacios privados en los que los señores pudieran deleitarse de los placeres de la intimidad y la comodidad, que tanto reconocimiento empezaron a adquirir durante aquel momento.

$\mathrm{Su}$ fachada principal miraba hacia la calle de la Emperatriz y estaba precedida de una entrada monumental en forma de plaza, mediante la cual mostrar a todo aquél que pasaba por delante el nivel de sus moradores. Mientras, el resto del palacio se encontraba rodeado por un jardín, que dotaba a la construcción de ese entorno natural tan apreciado en la época ${ }^{32}$.

Para concluir con Buenavista y su significado, es pertinente traer al texto la afirmación atribuida al arquitecto Martín Rodríguez, en un certificado que expidió a cerca del estado de las obras del palacio poco antes de la muerte de la duquesa de Alba en 1802: «... con destino para habitación de Señores de la clase de Grandes» ${ }^{33}$. Se ceñía de este modo a los postulados establecidos en los tratados de arquitectura sobre que la vivienda había de tener un grado de esplendor conforme a su fin y sin desdecir el carácter que se debía a los que la habrían de habitar ${ }^{34}$.

\subsection{La casa-palacio del Marqués del Campo de Villar en la calle de Atocha}

El II Marqués del Campo de Villar, don Alonso Muñiz Manjón, Mayordomo de Semana del Rey, contrajo matrimonio con doña Micaela de Laisequilla, hija legítima y heredera de don José de Laisequilla, que había sido Decano del Real Consejo y Cámara de Indias. Aquélla heredó a la muerte de su padre unas casas en la calle de Atocha que hacen esquina y buelben a la de las Vrosas ${ }^{35}$. Dichas casas habían sido llevadas al matrimonio por la esposa de don José de Laisequilla y madre de doña Micaela, doña

31. Ibídem. p. 285.

32. Portela Sandoval, Francisco José: El palacio de Buenavista. Cuartel General del Ejército. Madrid, 1996.

33. MARTÍNEZ FRIERA, J.: Op. cit., p. 330.

34. RIEGER, Christiano: Elementos de toda la architectura civil con las más singulares observaciones de los modernos. Traducción P. Miguel Benavente, Madrid, 1763. p. 48.

35. AHPM. Po 18523, f. 194 v. 
María Ana Pérez Dardón, y en ellas instalaron su residencia hasta la muerte de don José, en 1755, cuando las casas pasaron a su hija.

Fue entonces cuando se ordenó el derrumbe de aquellas casas principales y la construcción de una nueva vivienda al arquitecto don Andrés Díaz Carnicero. Su construcción finalizó en $1767^{36}$ y conocemos cómo se encontraban acondicionados sus interiores a través de la escritura del capital que don Alonso Muñiz aportó a su matrimonio ${ }^{37}$. Los bienes con los que acondicionó parte de la nueva residencia, tenían un doble origen, unos eran propiedad de don Alonso Muñiz Manjón, mientras otros habían llegado a su poder como parte de la herencia del que fuera su tío el I Marqués del Campo de Villar, don Alonso Muñiz Caso y Osorio, miembro del Consejo de Estado de su majestad, su Secretario del Despacho Universal de Gracia y Justicia ${ }^{38}$. Por lo tanto, los nuevos espacios habitacionales iban a mantener con frecuencia un estrecho lazo con las tradicionales casas principales, debido a que buena parte de los elementos que componían y vestían sus interiores tenían origen antiguo y ya habían ocupado las estancias de residencias pretéritas, por haber pertenecido a antepasados que los hubieran transmitido como herencia o por haber sido adquiridos en las almonedas que con frecuencia se realizaban con los bienes de un difunto.

Cierta continuidad se percibe, asimismo, con las casas principales, en la estructura en enfilade de que se dotaban las zonas de representación de estos nuevos palacios urbanos. Pese a la aparición de los apartamentos «privados», que comenzaron a servirse de espacios de paso como los pasillos, para conservar la intimidad en los aposentos, sin que hubiera que atravesarlos para llegar hasta el de destino; las zonas de representación continuaron manteniendo aquella disposición por la que todas las estancias se situaban en una misma línea recta o fila -el modelo tradicional se componía de antesala, sala y alcoba de aparato- y desde que el individuo se situaba en la puerta de la primera, conseguía una perspectiva visual a través de las puertas, asimismo, alineadas, del resto de estancias. Las puertas vidrieras de alcoba que aparecen anotadas en la cuenta de capital de don Alonso nos ratifican en dicha afirmación: un par de puertas vidrieras de alcova con quarenta y dos vidrios entrefinos en doscientos noventa y un reales $^{39}$. Lo que nos presentan estas puertas es una alcoba de aparato o representación que ser capaces de percibir desde la antecámara a través de los vidrios.

\subsection{El palacio de Liria}

El palacio de Liria se construyó durante la segunda mitad del siglo XVIII para servir de residencia a una de las familias de la nobleza instalada en la Corte, los Duques de Berwick y Liria.

\footnotetext{
36. SAltillo, Marqués del.: «Casas madrileñas del siglo XVIII y dos centenarias del siglo XIX» en Arte español. 1948. p. 30.

37. AHPM. Po. 18538, f. 366.

38. Ibidem.

39. АHPM. Po 18538 , f. 375.
} 
Esta casa nobiliaria, originaria de Inglaterra, descendía de forma directa del monarca Jacobo II. Jacobo Arabella, duque de Marlborough, fue hijo natural de Jacobo II y padre del mariscal Berwick, a quien por su destacada labor en la batalla de Almansa, durante la guerra de Sucesión, Felipe V le concedió el título de Duque de Liria.

El vínculo de dicha familia con España se estableció a través del matrimonio del II Duque de Liria con Catalina Ventura Colón de Portugal, Duquesa de Veragua. Pero, fue el III duque de Liria, don Jacobo Fitz James Stuart, hijo legítimo de este matrimonio, y casado desde 1738 con doña María Teresa Álvarez de Toledo, hija de la XI Duquesa de Alba, quien ordenó la construcción del palacio al que nos referiremos ${ }^{40}$. No obstante, su cargo de embajador en París le mantuvo durante largas temporadas fuera de la Corte y decidió delegar el control de las obras en su hermano, don Pedro Stuart y Colón, Marqués de San Leonardo, que le informaba puntualmente del desarrollo de la construcción a través de una fluida correspondencia epistolar ${ }^{41}$.

Del año 1762 datan los primeros indicios de la obra, sin embargo, hasta 1773 no fue encargada definitivamente al arquitecto Ventura Rodríguez, con cuyo proyecto de fachada contamos en la actualidad (Fig. 2). El palacio de Liria se erigió como un conjunto arquitectónico situado en los Altos de San Bernardino, por lo tanto, fuera ya del núcleo urbano madrileño. Se trataba de un espacio natural, en los límites de la cerca madrileña, donde existía la amplitud necesaria como para desarrollar una empresa del grado de la que se pretendía. De su estructura cabe destacar la multiplicación y diversificación de estancias interiores acomodadas cada una de ellas para cubrir las nuevas necesidades de intimidad y confort. Por otra parte, aquel espacio permitió la construcción de un jardín, siguiendo los preceptos procedentes de Europa, en el que mantener un contacto permanente con la naturaleza; o una plaza que precedía a la fachada principal, como fórmula integradora del edificio en la retícula urbana y que además sirviera de elemento de representación, para que todo el que pudiera verla, se hiciese una idea del nivel de ostentación del edificio al que antecedía aquel lugar de tal monumentalidad.

Para poder llevar a cabo dicha construcción, el Duque de Berwick tuvo que pedir permiso al Municipio de Madrid. Su propuesta consistía en el intercambio de «un trozo de la calle de San Dimas por otros más extensos de las calles de las Negras y de San Bernardino, que le consienta formar delante del Palacio que construye una plaza [cuyo diseño acompaña a la solicitud], que le despeje y deje lucir en beneficio del ornato

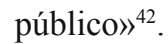

Los datos relativos al interior de esta casa-palacio de que disponemos, los obtenemos a través del análisis de la escritura de dote otorgada por el Duque de Berwick

40. Paz EsPeso, Julián: Árboles genealógicos de las Casas de Berwick, Alba y agregadas, $2^{\circ}$ edición, Madrid, 1948. SÁnchez CANTón, Francisco Javier: El palacio de Liria. Pasado y presente. Madrid, 1956. Martínez MedinA, África: Palacios madrileños... Op. cit. pp. 107-109.

41. Cepeda AdÁn, José.: «El Madrid de Carlos III en las cartas del marqués de San Leonardo» en Anales del Instituto de Estudios Madrileños, I (1966), pp. 219-230.

42. SÁNCHEZ CANTÓN, Francisco Javier: El palacio de Liria... p. 20. 
y Liria, don Jacobo Fitz James Stuart, con motivo de su matrimonio con doña María Teresa Silva y Palafox, hija de don Pedro Alcántara Fadrique, Duque de Híjar ${ }^{43}$.

Los elementos que hallamos en ella son esencialmente femeninos. Generalmente, las futuras novias eran dotadas principalmente con el que iba a componer su vestuario -ropa interior y vestidos-, con sus joyas -sortijas, pendientes, detalles para el pecho, alfileres-y en este caso particular, debido a su calidad, aportaba además los elementos necesarios para acondicionar las estancias de su uso dentro de la vivienda, espacios que podríamos denominar como femeninos.

Se nos presenta un tocador que estaba compuesto en su totalidad por elementos de plata. La silla de aquél se encontraba realizada en madera dorada y vestida con una falda de raso, guarnecida de glasé de plata, galón, fleco y borlas de oro... todos ellos textiles de la mayor riqueza y ostentación, representativos de la categoría de la persona destinada a ocuparlo. Se convierte así el tocador en un «espacio» singular, ya se encontrara en una estancia separada o integrado dentro de la cámara, en extraordinario objeto de representación debido a los metales preciosos que lo componían o las telas que lo revestían.

También formaba parte de esta dote un conjunto textil cuyo destino era servir como cubierta de sala. La tendencia que apreciamos para el tocador se repite, las telas en que están confeccionadas son algunas de las más valiosas del mercado -glasé de plata, tafetán, fleco de oro, espiguilla de plata-. No obstante, aparecen, asimismo, inventariados otros juegos más ordinarios que servirían para sustituir a los primeros en las ocasiones que la etiqueta lo permitiera.

Finalmente, hallamos mención de la camilla que ocupaba el retrete, construida de herraje y vestida de damasco carmesí y galón de oro. Esta anotación, nos acerca a un espacio dentro de la vivienda que poco tiene que ver con lo que a día de hoy entendemos por retrete. Entonces era entendido como una habitación de pequeñas dimensiones destinada al retiro del individuo. El mueble que se asociaba a ella, una camilla, definida por el Diccionario de la Real Academia como una especie de cama «La que sirve para estar medio vestido en ella, como lo hacen las mujeres cuando se empiezan a levantar después de haber parido o están de duelo», nos induce a su concepción como un espacio íntimo de la mujer.

Frente a las referencias antecedentes, que nos aproximan a espacios destinados a cubrir esas nuevas necesidades de los individuos, la figura del cofre nos remite a la tradición. El cofre aparecía, todavía a finales de siglo en algunos de aquellos espacios, con valor de mueble contenedor del lote dotal que aportaban las novias a su matrimonio, y pese a su inferior funcionalidad, con respecto a los nuevos muebles contenedores que habían ido surgiendo a lo largo del siglo -cómodas-, su presencia permanecía en las dotes femeninas como un símbolo de la tradición familiar.

43. AHPM. Po 21532, f. 52-67. 


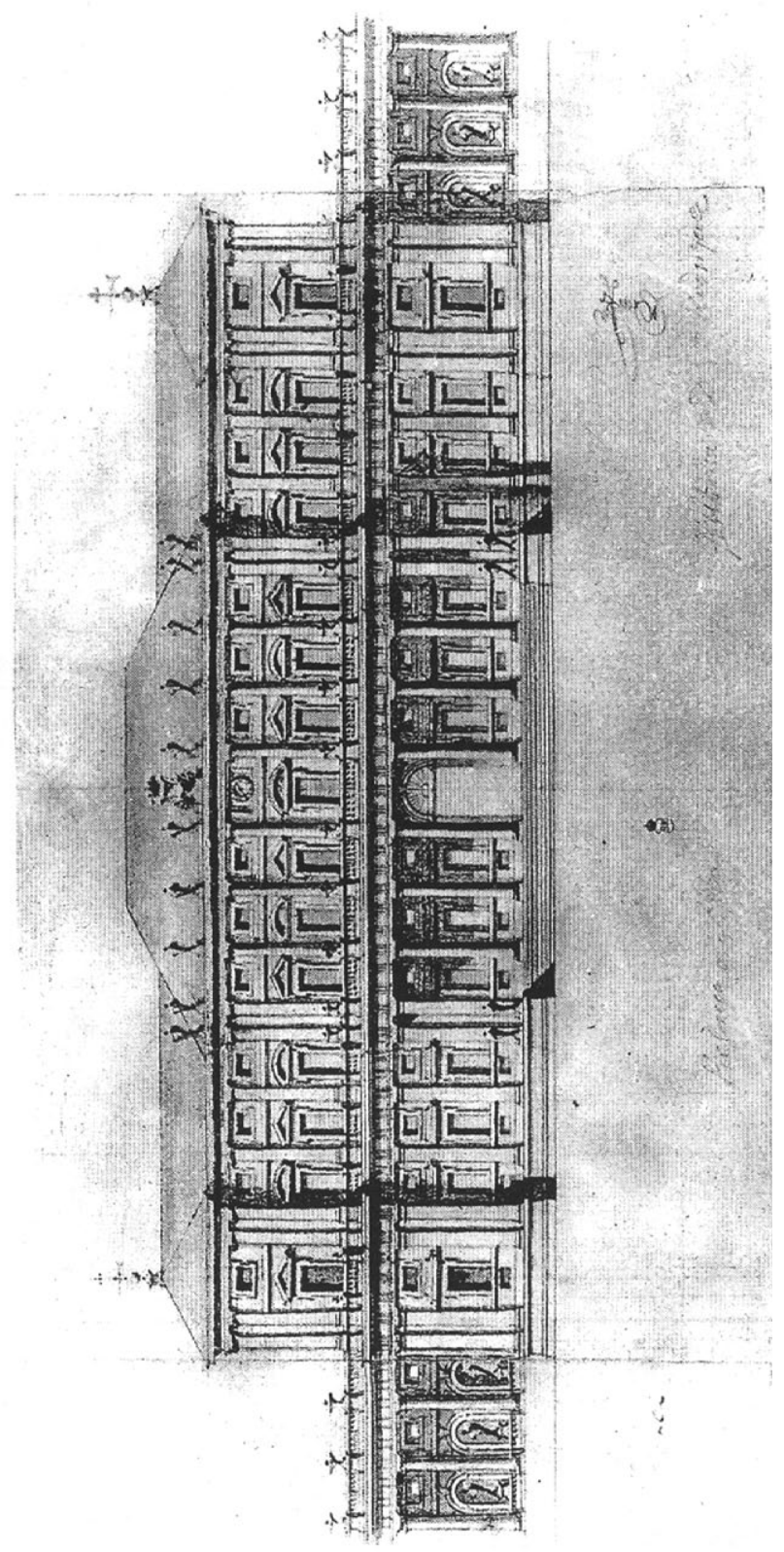

Figura 2. Proyecto para el Palacio del Duque de Liria: alzado de la fachada ${ }^{44}$

44. BN. DIB 14/25/20.

REVISTA DE HISTORIA MODERNA Nº 30 (2012) (pp. 47-66) ISSN versión electrónica: 1989-9823 


\subsection{El palacio de la Marquesa de Astorga en la calle de San Bernardo}

Don Ventura Osorio de Moscoso y Guzmán, que falleció en 1776 ejerciendo el cargo de Caballerizo Mayor del Príncipe de Asturias ${ }^{45}$, fue el promotor de la edificación de la casa-palacio que los titulares del marquesado de Astorga disfrutaron en la calle Ancha de San Bernardo de la capital -manzana 467 de la Planimetría ${ }^{46}$ - . La calle Ancha de San Bernardo se definió por ser una de las calles nobiliarias por excelencia en Madrid, debido al importante número de casas principales que en ella se podían encontrar.

Don Ventura encargó la realización del proyecto de su palacio al arquitecto Ventura Rodríguez a comienzos de los años setenta. Los terrenos elegidos para su materialización fueron aquellos en los que los Marqueses de Leganés poseyeron, ya desde mediados del siglo XVII, sus casas principales. Dichas casas principales habían sido trazadas por el arquitecto Juan Gómez de Mora, componiendo un conjunto constructivo de los tan característicos en el siglo XVII.

La construcción del nuevo palacio hizo necesario el derrumbe de las casas precedentes $^{47}$. Los planos con los que contamos sobre el edificio palacial que se proyectót ${ }^{48}$ muestran una vivienda de planta rectangular que articulaba sus estancias en torno a un patio central. La distribución de las plantas -baja y principal-seguía los preceptos emanados desde la tratadística arquitectónica. Cocinas, despensas, cocheras y caballerizas se situaban en la planta baja, alejando molestos olores y ruidos de la planta principal o noble, donde se encontraban los apartamentos de los señores y las salas de recibir.

El inventario de bienes realizado en 1803 a la muerte de Doña María de la Concepción Guzmán ${ }^{49}$, Marquesa de Astorga y Condesa de Altamira, viuda del referido don Ventura y madre de don Vicente Joaquín, heredero del título, nos ofrece una excelente imagen de los espacios interiores de su palacio, mostrando los elementos contenidos en estos.

En primer lugar, prestaremos atención a la referencia que se menciona sobre uno de los espacios femeninos por antonomasia, la recámara de la señora. Estamos de nuevo ante una de esas pequeñas piezas que aparecían en torno a la cámara y que formaban parte de la zona femenina de la casa. Los muebles que aparecían en dicha estancia estaban tallados sobre maderas finas y consistían principalmente en un conjunto de sillas, mesas en las que se multiplicaban las gavetas, los cajones, las puertas -caben ser distinguidos el tocador, el bufete con su estante para colocar libros o la papelera-,

45. Sobre su biografía FICHOZ 014509.

46. BN, Mss. 1675, Planimetría General de Madrid. Libro quinto de los asientos de las casas, pp. 369-370.

47. Martínez MedinA, África. «La casa palacio del Marqués de Astorga» en Anales del Instituto de Estudios Madrileños. XXVII (1989), pp. 121-133 y Palacios madrileños... Op. cit. p. 61-72.

48. Planta del piso bajo. Madrid, Museo Municipal I.N. 3080 y planta del piso principal. Madrid, Museo Municipal 3081.

49. AHPM. Po 22255, f. 366. 
muebles contenedores -armarios guardarropas, librerías de puertas enrejadas que dejaran ver los títulos de los libros, baúles-.

Pese a su carácter, eminentemente íntimo, los objetos custodiados en ella eran de un lujo exquisito -elaborados en plata y primorosamente labrados-. Aquellos estaban enfocados a diferentes usos -servicio de mesa, de tocador para el aseo y afeite personal de la señora, destinados a su actividad escritora, sus joyas y alhajas de adorno personal-. Estas connotaciones nos llevan a valorar determinados aposentos en una posición intermedia entre la emergente esfera de lo íntimo que empezó a fraguarse durante este siglo dentro del entorno doméstico y la tradicional, pública y de representación, de espacios que se vestían para deslumbrar al que los visitaba.

Por otra parte, el inventario de bienes de la Marquesa de Astorga nos aproxima al terreno de las prácticas lúdicas que se llevaban a cabo dentro de la vivienda aristocrática. El juego se convertiría en elemento central en algunas de las reuniones desarrolladas en aquel entorno doméstico, aunque también habría de ocupar ciertos momentos de intimidad familiar. Probablemente, no existía dentro de la casa una sala determinada destinada al juego, no encontramos mención sobre ella en la documentación. Sin embargo, las mesas cuyos tableros servían de soporte a los distintos juegos, dada su cualidad de plegarse, podrían ser transportadas a una sala u otra, según el número de participantes o las circunstancias lo exigieran. Los juegos que pudieron entretener las horas de ocio en palacio se citan de la forma siguiente en el recuento de bienes:

«Tres juegos de lotería, los dos con caja de cartón y el otro con caja de nogal 200 reales de vellón

Otra caja de nogal con juego de lotería completo 100 reales de vellón

Una caja acharolada de Indias con quatro cajitas pequeñas con fichas de nácar 60 reales de vellón

Otra caja con quatro pequeñas dentro con fichas de hueso 16 reales de vellón

Otra caja con una porción de fíchas de varios colores 40 reales de vellón

Otra caja pequeña de nácar con fichas de lo mismo 80 reales de vellón

Dos juegos de dominó y uno de rentilla 24 reales de vellón

Un juego de oca 12 reales de vellón

Una caja con quatro cajitas dentro pintadas con fichas 30 reales de vellón

Un juego de vis vis completo 160 reales de vellón» ${ }^{50}$.

Finalmente, la tasación que se ejecutó de la biblioteca de doña María de la Concepción, nos obliga a reparar en el desarrollo de la práctica de la lectura dentro de la vivienda palacial. El amplio número de libros de temática variada -obras religiosas, teatrales, narrativa de los siglos XVII y XVIII, novela sentimental, prensa- que se inventarió podía estar ubicado en una estancia en la planta principal, que se documenta específicamente denominada como biblioteca. La aparición de este tipo de pieza es

50. AHPM. $\mathrm{P}^{\mathrm{o}} 22255$, f. 377-378. 
significativa de unos hábitos no sólo de lectura, sino también de coleccionismo bibliófilo que conllevan estudios en profundidad que actualmente se están llevando a cabo ${ }^{51}$.

\section{CONCLUSIONES}

Una vez nos hemos introducido, en unos casos con mayor y en otros con menor fortuna, según la documentación nos lo ha permitido, en casas principales y palacios de la nobleza cortesana, podemos finalizar apuntando una serie de características, bien podríamos decir, generales, para cada una de las tipologías.

Ambos modelos coincidían en concederle amplios espacios a las zonas de representación. La aristocracia mantuvo durante todo el siglo XVIII, pese a la transformación que se pudo percibir en otro tipo de valores y comportamientos, la práctica de mostrar y exhibir su poder político, social y económico a través de los niveles materiales que conformaban sus espacios de habitación cotidiana.

No obstante, en las nuevas construcciones palaciales que surgieron durante la segunda mitad de la centuria, las estancias concebidas para lo privado y lo íntimo comenzaron a ganar terreno.

Asimismo, es importante incidir en la presencia de importaciones extranjeras. Ya se tratara de imitación de modelos, como se percibe desde comienzos de siglo con el uso de chimeneas al estilo francés, o con la impronta que inundaba las estructuras palaciales en todo su conjunto avanzada ya la centuria; o con la presencia de objetos procedentes de otros territorios: sillas inglesas, relojes ingleses, tejidos italianos... Lo que queda de manifiesto es la atracción de esta elite por lo foráneo y que poseían los medios necesarios para hacerse con ello. No entramos a valorar su capacidad económica, que indiscutiblemente, era suficiente para poder permitirse aquel tipo de adquisiciones -aunque en ciertas ocasiones se haya puesto en duda si hubieran podido permitirse mucho más-, lo que sí queda demostrada es la existencia de una serie de canales físicos -infraestructuras mercantiles-y simbólicos - pedagógicos-mediante los cuales transmitir productos e ideas a un grupo social incipientemente permeable y en proceso de transformación.

51. En un intento de profundizar en las prácticas femeninas concernientes al libro dentro del ámbito doméstico vid. Ortego Agustín, Ángeles: «La lectura en el ámbito doméstico. Placer personal y afición cotidiana. La biblioteca femenina de la Marquesa de Astorga» (en prensa) y GoNZÁLEZ HERAS, Natalia: «La biblioteca de la Duquesa viuda de Arcos» (en prensa). 